\title{
Low Mannose-Binding Lectin (MBL) genotype is associated with future cardiovascular events in type 2 diabetic South Asians. A prospective cohort study
}

\author{
Machiel A Siezenga ${ }^{1 *}$, Prataap K Chandie Shaw², Mohamed R Daha', Ton J Rabelink ${ }^{1}$ and Stefan P Berger ${ }^{1,3}$
}

\begin{abstract}
Background: South Asians have a high burden of type 2 diabetes and vascular complications. Vascular inflammation is considered central in the pathophysiology of atherosclerosis, and the complement system is thought to play an important role. Mannose-Binding Lectin (MBL), which activates the lectin pathway of complement activation, has been introduced as a risk marker of vascular damage. The present study explores the association of MBL levels, genotype and cardiovascular events in type 2 diabetic South Asians.

Methods: We conducted a prospective observational study. A cohort consisting of 168 type 2 diabetic South Asians was followed for a median duration of 7.66 years. At baseline, MBL levels and genotype were determined. The association with future cardiovascular events was assessed by Cox proportional hazard regression.

Results: During follow-up, 31 cardiovascular events occurred in 22 subjects (11 men, 11 women). The O/O genotype was significantly associated with the occurrence of cardiovascular events (hazard ratio 3.42, 95\% $1.24-$ 9.49, $\mathrm{P}=0.018$ ). However, log MBL levels were not associated with the occurrence of cardiovascular events (hazard ratio $0.93,95 \% \mathrm{Cl} 0.50-1.73)$.
\end{abstract}

Conclusions: In type 2 diabetic South Asians, the O/O MBL genotype is associated with cardiovascular events, although single serum MBL levels are not.

Keywords: South Asians, type 2 diabetes, cardiovascular disease, Mannose-binding lectin (MBL)

\section{Introduction}

South Asian immigrants in Western societies have a high burden of diabetes and vascular complications [1]. Traditional cardiovascular risk factors only partially explain this increased risk [2]. Hence other factors must be involved.

Atherosclerosis, the pathologic substrate of macrovascular disease, is recognized to be an inflammatory process [3]. As a player in the inflammatory response, the complement system is thought to be involved in this vascular inflammation [4] Indeed, complement

\footnotetext{
* Correspondence: m.a.siezenga@lumc.nl

'Department of Nephrology, Leiden University Medical Center, Leiden, the Netherlands

Full list of author information is available at the end of the article
}

activation products have been demonstrated in atherosclerotic plaques [5].

The complement system can be activated via the classical, alternative or lectin pathway, which is activated when Mannose-Binding Lectin (MBL) binds to its target molecule. MBL binds carbohydrate moieties on microorganisms. However, endogenous MBL ligands, such as glycosylated immunoglobulins or cells exposed to oxidative stress, have also been identified [6]. MBL serum levels are primarily determined by 3 polymorphisms (B, $\mathrm{C}$ and $\mathrm{D}$ genotypes, commonly referred to as $\mathrm{O}$-alleles) in the MBL gene (mbl2). Subjects with wild type MBL genotype (A/A) have the highest serum MBL levels, subjects with 1 variant allele $(\mathrm{A} / \mathrm{O})$ have intermediate levels and subjects with 2 variant alleles $(\mathrm{O} / \mathrm{O})$ have the lowest levels. In addition, polymorphisms in the promoter 
region influence the MBL level [7]. MBL is synthesized in the liver. Although intraindividual levels are relatively stable over time [8], a two-to threefold increase occurs during acute phase reactions [9].

It has recently been suggested that MBL is involved in the pathophysiology of cardiovascular damage in highrisk populations [10]. In a group of type 1 diabetic Caucasians, MBL levels were significantly higher in subjects with either a history of cardiovascular disease or diabetic nephropathy compared to subjects without these vascular complications [10]. In type 2 diabetic Caucasians high MBL levels were associated with increased mortality [11]. However, others found an association between low MBL levels and cardiovascular events [8,12]. Data on MBL in South Asians are lacking.

We hypothesized that MBL might be involved in the high incidence of cardiovascular complications in type 2 diabetic South Asians. The current study aims to explore the association of MBL levels and genotype with cardiovascular complications in type 2 diabetic South Asians. We demonstrate that a low MBL genotype is associated with cardiovascular events, while a single serum MBL level is not.

\section{Research design and methods}

\section{Design of the follow-up study}

We conducted a prospective cohort study. All studied subjects were recruited from a previously published study [13]. The original study population comprised 465 South Asians. At baseline, subjects that were not known with diabetes underwent a $75 \mathrm{~g}$ oral glucose tolerance test. Diabetes was diagnosed based on the ADA 2003 criteria. Out of 465 subjects, 168 subjects had type 2 diabetes at baseline (122 already known with diabetes, 46 newly diagnosed), and from these subjects follow-up data were collected. The study protocol was approved by the Institutional Medical Ethics Committee. All subjects provided informed consent.

Study-patients were followed up by letter and subsequently by phone. When subjects could not be traced by address or phone number in our database, general practitioners or participating family members were involved.

Follow-up data consisted of medical history with regard to cardiovascular events. Subjects were sent a questionnaire and were invited for a visit to our outpatient clinic. During this visit the questionnaire was reviewed by the main investigator (M.A.S.). Subjects not willing to visit the out-patient clinic were asked permission to collect medical data from their general practitioner. For subjects who had died during the follow-up period, cause of death and cardiovascular history was retrieved from the general practitioner. All (self-) reported events were verified by contacting the hospital in which the event had occurred.

\section{Measurements at baseline}

Laboratory measurements at baseline included lipids, creatinine, fasting glucose, urinary albumin/creatinine ratio, high-sensitivity C-reactive protein (hsCRP), and plasma SC5b-9, the soluble end product of complement activation. Lipids, creatinine, glucose and urinary albu$\mathrm{min} /$ creatinine ratio were measured according to standard methods. High-sensitivity C-reactive protein was measured with a fully automated Cobas Integra 800, according to the manufacturers proceedings (Roche, Almere, the Netherlands). The variation coefficients (VC) were below 3\%. Plasma levels of SC5b-9 were measured with an ELISA as described earlier [14].

\section{MBL genotyping}

DNA was isolated routinely from peripheral blood leucocytes. MBL single nucleotide polymorphisms at codons 52,54 and 57 of the $m b l 2$ gene were typed by pyrosequencing. The detailed methodology has been published separately [15]. The MBL genotype of only wildtype allele carriers is designated as $\mathrm{A} / \mathrm{A}$ and the presence of 1 or 2 variant alleles(s) (B, C, or D) is designated as $\mathrm{A} / \mathrm{O}$ or $\mathrm{O} / \mathrm{O}$, respectively.

\section{Serum MBL levels}

At baseline, serum MBL levels were assessed by sandwich ELISA as described previously [16]. In brief, 96well ELISA plates (Greiner, Frickenhausen, Germany) were coated with the monoclonal antibody 3E7 (mouse IgG1 anti-MBL at $2.5 \mathrm{mg} / \mathrm{ml}$ ), kindly provided by Dr. T. Fujita (Fuhushima, Japan). Serum samples were diluted $1 / 50$ and $1 / 500$ and incubated in the coated wells. MBL was detected with Dig-conjugated 3E7. Detection of binding of Dig-conjugated antibodies was performed using HRP-conjugated sheep anti-Dig Abs (Fab fragments, Roche, Mannheim, Germany). Enzyme activity was detected using 2,2'-azino-bis(3-ethylbenzthiazoline-6-sulfonic acid) (Sigma Chemical Co., St. Louis, MO)). The optical density was measured at $415 \mathrm{~nm}$ using a microplate biokinetics reader (EL312e; Biotek Instruments, Winooski, VT). A calibration line was produced using human serum from a healthy donor with a known concentration of MBL. Earlier studies indicated that this assay primarily detects wildtype MBL in serum and plasma and that there is a direct association with the MBL genotype and with MBL function [17].

\section{Definition of endpoint}

Cardiovascular events were defined as the occurrence of either a myocardial infarction, Percutaneous Transluminal Coronary Angioplasty (PTCA), Coronary Artery Bypass Grafting (CABG), or sudden cardiac death. The latter was defined as a witnessed sudden circulatory 
arrest. The primary end-point was the time to the first cardiovascular event.

\section{Statistical analysis}

Normally distributed variables are expressed as arithmetic mean \pm 1 standard deviation. Skewed distributed variables are expressed as median with interquartile range.

Differences between groups were assessed with the independent samples t-test or the Mann-Whitney-U test for normally and not-normally distributed variables respectively. Comparison between multiple groups was performed with analysis of variance. Correlations were assessed by using Pearson's correlation and Spearman's correlation as appropriate. Associations with cardiovascular events were assessed by Cox proportional hazard regression...All tests were two-sided and the level of significance was set at 0.05 .

All analyses were performed using SPSS Statistical Software Package (version 17.0; SPSS, Chicago, IL)

\section{Results}

\section{Baseline analysis}

At baseline, serum MBL levels and MBL genotype were determined in 168 diabetic subjects (122 already known with diabetes, 46 newly diagnosed). DNA was not available in 5 diabetic patients.

The median MBL level was $476 \mu \mathrm{g} / \mathrm{L}$ (IQR 143-1536 $\mu \mathrm{g} / \mathrm{L})$. Genotype distribution in South Asians was the same as the reported genotype distribution in Caucasians [7]. MBL levels differed significantly per genotype $(\mathrm{P}<0.001)$ : subjects with the A/A genotype had the highest MBL levels (median $1300 \mu \mathrm{g} / \mathrm{L}$, IQR 535-2258) with the A/O genotype had intermediate MBL levels (median $160 \mu \mathrm{g} / \mathrm{L}, \mathrm{IQR} 75-295$ ) and subjects with the $\mathrm{O} / \mathrm{O}$ genotype had the lowest MBL levels (median 74 $\mu \mathrm{g} / \mathrm{L}, \mathrm{IQR} 38-101$ ).

MBL levels correlated weakly with BMI $(\mathrm{r}=-0.155$, P $=0.014), \mathrm{HbA} 1 \mathrm{c}(\mathrm{r}=0.165, \mathrm{P}=0.034)$ and hip circumference $(-0.169, \mathrm{P}=0.030)$, but not with sex, age, blood pressure, high-sensitivity C-reactive protein (hsCRP), smoking status, total cholesterol, fasting triglycerides, and plasma SC5b-9.

\section{Longitudinal analysis}

Out of 168 type 2 diabetic subjects at baseline, 21 could not be traced and 13 subjects refused to participate and thus were excluded from analysis. Eighty-six subjects visited the out-patient clinic, 31 subjects did not visit the out-patient clinic but medical information was retrieved from the general practitioner, and 17 subjects had died (see below). The median duration of follow-up was 7.66 (IQR 7.48-8.10) years. Participants lost to follow-up did not differ in baseline characteristics from participants for whom follow-up data were available (table 1).

During follow-up, 31 cardiovascular events occurred in 22 subjects ( 11 men, 11 women): 3 sudden cardiac deaths, 2 fatal and 5 non-fatal myocardial infarction, 13 percutaneous coronary interventions, and 8 coronary artery bypass graft procedures. Eight of these 22 subjects had already experienced a cardiovascular event at baseline.

Twelve subjects died due to non-cardiovascular causes. These patients were censored, none of them reached the primary end-point before dying.

Table 1 Baseline characteristics of the type 2 diabetic South Asian study population

\begin{tabular}{llll}
\hline & Follow-up $(\mathbf{n}=\mathbf{1 3 4})$ & Lost to follow-up $(\mathbf{n}=\mathbf{3 4})$ & P-value \\
\hline Age (years) & $50.7 \pm 11.2$ & $48.9 \pm 11.2$ & 0.392 \\
\% male sex & 46 & 45 & 0.886 \\
Diabetes duration (years) & $7.0(0-13)$ & $5.0(0-11)$ & 0.519 \\
HbA1c (\%) & $7.7 \pm 1.8$ & $7.7 \pm 2.0$ & 0.976 \\
Systolic blood pressure (mm Hg) & $138 \pm 24$ & $140 \pm 27$ & 0.638 \\
Diastolic blood pressure (mm Hg) & $84 \pm 11$ & $84 \pm 11$ & 0.937 \\
Urinary albumin/creatinine ratio (mg/mmol) & $1.0(0.4-4.6)$ & $1.0(0.4-5.0)$ & 0.991 \\
High-sensitivity C-reactive protein (mg/L) & $3.5(1.8-8.0)$ & $4.8(1.7-8.4)$ & 0.851 \\
Cockroft clearance (ml/min) & $86 \pm 27$ & $93 \pm 20$ & 0.205 \\
Total cholesterol (mmol/L) & $5.1 \pm 1.0$ & $5.0 \pm 0.9$ & 0.666 \\
Fasting triglycerides (mmol/L) & $1.59(1.16-2.32)$ & $1.46(1.24-2.13)$ & 0.869 \\
HDL-cholesterol (mmol/L) & $1.23 \pm 0.3$ & $1.28 \pm 0.3$ & 0.954 \\
Ratio total cholesterol: HDL-cholesterol & $4.14(3.45-5.05)$ & $4.20(3.10-5.0)$ & 0.432 \\
Body Mass Index & $28.0 \pm 4.7$ & $28.4 \pm 4.0$ & 0.551 \\
Waist-to hip ratio & $0.97(0.93-1.03)$ & $0.99(0.95-1.04)$ & 0.223 \\
\% previous cardiovascular event & 14 & 11 & 0.663 \\
\% current or previous smoker & 45 & 39 & 0.528 \\
\hline
\end{tabular}


Compared to the wild-type genotype, the $\mathrm{O} / \mathrm{O}$ genotype was significantly associated with the occurrence of a cardiovascular event (hazard ratio $3.43,95 \%$ CI 1.249.49, $\mathrm{P}=0.005$ ) (table 2 and table 3 Figure 1). Subjects with the $\mathrm{O} / \mathrm{O}$ genotype did not differ in lipid parameters or blood pressure compared to subjects with the A/A or $\mathrm{A} / \mathrm{O}$ genotype. The $\mathrm{A} / \mathrm{O}$ genotype was not associated with cardiovascular events (HR 0.65, 95\% CI 0.20-2.07). Cardiovascular events were also associated with a previous cardiovascular events (HR 4.3, 95\% CI 1.2-10.3) and $\log$ urinary albumin/creatinine ratio (HR 1.58, 95\% CI 1.0-2.48).

There was no statistically significant difference in baseline median MBL level between subjects experiencing a cardiovascular event during follow-up and subjects without a cardiovascular event $(390 \mu \mathrm{g} / \mathrm{L}$ (IQR 77$1348 \mu \mathrm{g} / \mathrm{L}$ ) versus $466 \mu \mathrm{g} / \mathrm{L}$ (IQR 139-1545 $\mu \mathrm{g} / \mathrm{L}$ ), $\mathrm{P}=$ 0.674). Log-transformed MBL levels were not associated with the occurrence of cardiovascular events (hazard ratio 0.93 , 95\% CI 0.50-1.73). MBL levels above the median were not associated with cardiovascular events (hazard ratio 0.94, 95\% CI 0.40-2.20). Using other MBL cut-off levels also failed to show an association with cardiovascular events (data not shown).

\section{Discussion}

From different parts of the world, South Asian ethnicity has been reported to be an independent risk factor for cardiovascular events $[1,18]$, although survival thereafter does not seem to be worse compared to Caucasians $[19,20]$. We studied the effect of MBL genotype and level in a group of type 2 diabetic subjects of South Asians descent.

The main finding of the present study is that in type 2 diabetic South Asians, the O/O MBL genotype was significantly associated with the occurrence of cardiovascular events compared to wild-type.
The association between low MBL genotype and cardiovascular events has previously been reported in different populations $[12,21,22]$. For instance, the Strong Heart Study included American Indians [12], which like South Asians-have a high burden of diabetes and subsequent vascular complications. A low MBL genotype was associated with a threefold increased risk for coronary heart disease.

With respect to serum MBL levels and cardiovascular events, data are more controversial. Cross sectional studies found higher MBL levels in type 1 and type 2 diabetic Caucasians with a previous cardiovascular event compared to diabetic subjects without cardiovascular disease $[10,11]$. In non-diabetic Caucasian males but not in females, high MBL levels were associated with future cardiovascular events [23]. In type 2 diabetic Caucasians high MBL levels were associated with increased all cause mortality, although data with respect to cardiovascular events were not reported [11]. In contrast, the prospective Reykjavik study found that in type 2 diabetic subjects low rather than high MBL levels were associated with increased incidence of myocardial infarction [8]. Recently, the Strong Heart Study provided data on MBL levels, confirming that low baseline MBL levels indeed were associated with future cardiovascular events [24]. In our study, MBL levels were not associated with future cardiovascular events.

A possible explanation for an association between low MBL levels and cardiovascular events might be a defective clearance of atherogenic particles. MBL binds $\mathrm{N}$-acetylglucosamine moieties, which are expressed on several lipoproteins and oxidized LDL [25], and this may facilitate their phagocytic clearance. This hypothesis is supported by a recently published study showing that MBL deficient subjects have impaired clearance of triglyceride-rich lipoproteins [26]. Additionally, MBL deficiency might influence the

Table 2 Median MBL level (interquartile range in brackets) and genotype distribution in study subjects according to ethnicity and cardiovascular complications

\begin{tabular}{|c|c|c|c|c|}
\hline & \multirow[t]{2}{*}{ Median MBL level } & \multicolumn{3}{|c|}{$\begin{array}{c}\% \mathrm{MBL} \text { genotype } \\
\text { (absolute number in brackets) }\end{array}$} \\
\hline & & $A / A$ & $\mathrm{~A} / \mathrm{O}$ & O/O \\
\hline \multicolumn{5}{|l|}{ Cross sectional } \\
\hline South Asians ( $n=168)$ & 476 g/L (143-1536) & $57(93)$ & $35(58)$ & $8(13)^{*}$ \\
\hline Caucasians [7] & & 60 & 36 & 4 \\
\hline \multicolumn{5}{|l|}{ Longitudinal } \\
\hline cardiovascular event ${ }^{\dagger}(n=22)$ & 390 g/L (77-1348) & $50(11)$ & $20(4)$ & $30(7)^{\ddagger}$ \\
\hline no cardiovascular event (112) & 466 g/L (139-1545) & $56(63)$ & $37(41)$ & $7(8)$ \\
\hline
\end{tabular}

\footnotetext{
${ }^{\dagger}$ Cardiovascular event: see text for definition

*P $=0.226(\% \mathrm{O} / \mathrm{O}$ in South Asians compared to Caucasians)

${ }^{\ddagger} \mathrm{P}=0.004$ (\% O/O in subjects with cardiovascular event compared to subjects without cardiovascular event)
} 
Table 3 Association with cardiovascular events of the MBL genotype and serum MBL level

\begin{tabular}{lcc}
\hline & Hazard Ratio & $\mathbf{9 5 \%} \mathbf{C l}$ \\
\hline MBL genotype & & \\
A/A $(n=74)$ & 0.65 & $0.20-2.07$ \\
A/O $(n=42)$ & 3.43 & $1.24-9.49$ \\
O/O $(n=13)$ & 1.26 & $0.52-3.04$ \\
Combined A/O and O/O & \\
& & \\
Log MBL level (per log MBL increase) & $0.50-1.73$ \\
Crude & 0.93 & $0.61-2.30$ \\
Adjusted $^{a}$ & 1.19 &
\end{tabular}

${ }^{a}$ Adjusted for urinary albumin/creatinine ratio, log high sensitivity CRP, waistto-hip ratio, smoking status, ratio total cholesterol: HDL-cholesterol, systolic blood pressure, age, sex, HbA1c, diabetes duration

susceptibility and course of infection with Chlamydia pneumoniae, which is associated with coronary artery disease [27]. On the other hand, MBL levels may increase in the setting of an inflammatory response [9]. Experimental studies show that in the setting of ischemia/reperfusion high MBL levels are detrimental rather than protective [28]. Oxidative stress induces a change on the cellular surface [29], which results in binding of MBL leading to enhanced complement mediated injury. However, since MBL levels were not correlated with plasma SC5-9 levels in our study, we found no evidence that high MBL levels result in increased complement activation.
Summarizing the above, whereas most cross sectional studies found an association between cardiovascular disease and high MBL levels, most prospective studies show an association between low MBL levels and cardiovascular events.

In our study, low MBL genotype was associated with cardiovascular events and MBL genotype corresponds with MBL level. One would therefore expect low MBL levels to be associated with cardiovascular events, which however was not the case in our study. MBL genotype probably is a more accurate estimate of cumulative MBL exposure than a single serum MBL level. The contribution of MBL to vascular disease might differ according to the pathophysiologic phase: early in the course low MBL levels might promote atherosclerosis, and once a vascular inflammatory response is established MBL levels might secondarily become increased and - perhaps - subsequently promote vascular inflammation. A recent experimental study demonstrated local MBL synthesis in early atherosclerotic plaques [30], supporting the hypothesis that MBL levels might become increased due to atherogenesis. Based on the assumption of time-dependency of the association between MBL and cardiovascular disease, our single baseline sample might have been too late in the pathophysiologic course to detect the effect of low MBL level on cardiovascular outcome. In addition, intra-individual variation in MBL level and variations of the MBL assay might contribute to the discordant findings between MBL genotype and MBL level. Finally, at least theoretically, the association

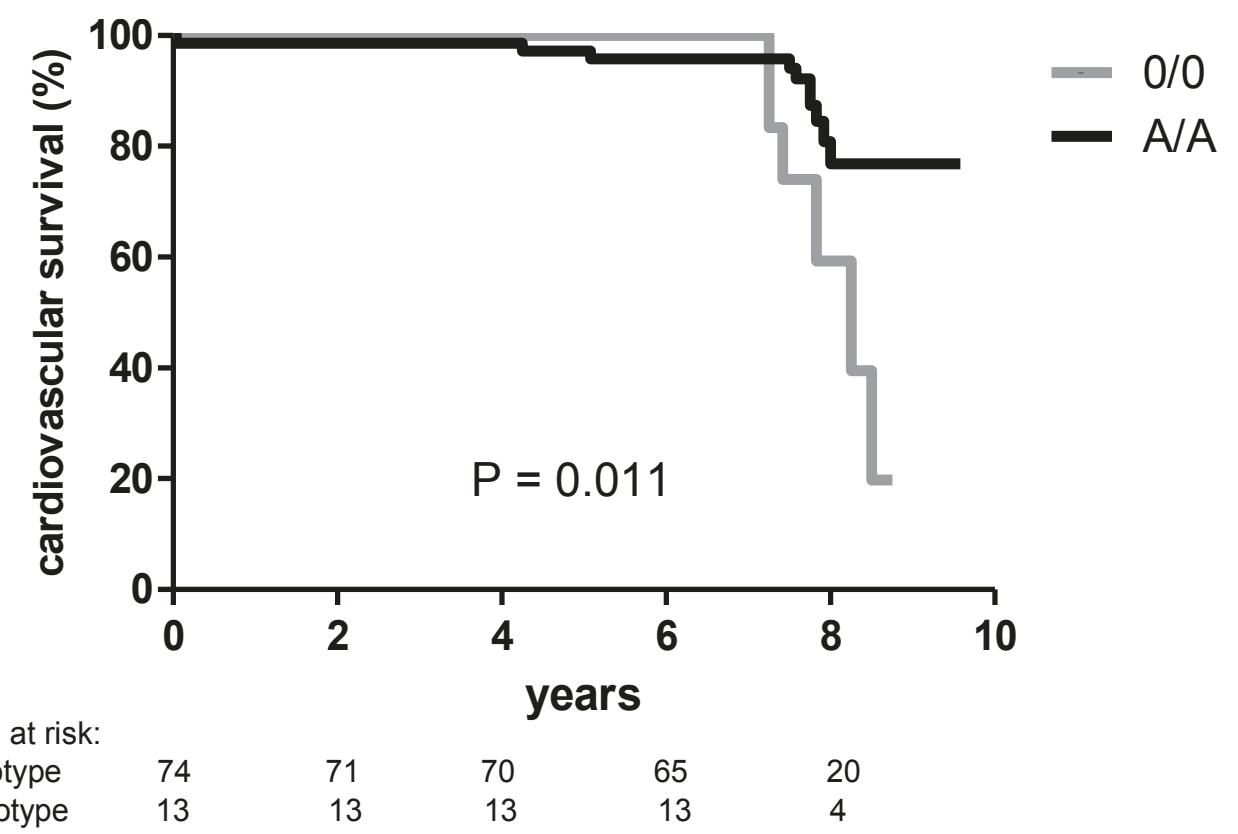

Figure 1 Unadjusted Kaplan-Meier survival curves according to MBL genotype (black line = A/A (wild type), grey line = O/O genotype). The $\mathrm{O} / \mathrm{O}$ genotype has a worse event-free survival compared to the $\mathrm{A} / \mathrm{A}$ genotype (Log rank test $\mathrm{P}=0.011$ ). 
of low MBL genotype with cardiovascular events might be based on an association with other susceptibility genes for cardiovascular events.

Noteworthy, although the $\mathrm{O} / \mathrm{O}$ genotype was associated with cardiovascular events, the $\mathrm{A} / 0$ genotype was not, although the difference in median MBL level between the $\mathrm{O} / \mathrm{O}$ and the $\mathrm{A} / \mathrm{O}$ genotype was relatively small. However, it has previously been shown that although $\mathrm{MBL}$ concentration in $\mathrm{A} / \mathrm{O}$ and $\mathrm{O} / \mathrm{O}$ genotype is rather similar, functional capacity of MBL in carriers of the O/O genotype is less compared to MBL of $\mathrm{A} / \mathrm{O}$ carriers. Functional MBL consists of polymers of 3 to 6 subunits. The number of structural variants influences the assembly of the MBL subunits, and lower polymerization grade results in loss of function [31].

We do want to point out that the results of our study may not apply to South Asians in general as the ancestors of the South Asians included in our study originally came from a circumscriptive area in North India called Uttar Pradesh, Uttarakhand and West-Bihar.

In conclusion, low MBL genotype is associated with cardiovascular events in type 2 diabetic South Asians, suggesting that MBL is involved in the pathogenesis of cardiovascular events. However, single serum MBL concentrations were not associated with cardiovascular events and therefore a single MBL level is not a clinically useful risk marker for cardiovascular events in type 2 diabetic South Asians.

\section{Abbreviations List}

A/A genotype: Wild type MBL genotype; A/O genotype: 1 structural variant; HR: Hazard Ratio; MBL: Mannosebinding Lectin; O/O genotype: 2 structural variants.

\section{Acknowledgements}

We thank Reinier van der Geest and Nicole Schlagwein for technical assistance.

\section{Author details \\ ${ }^{1}$ Department of Nephrology, Leiden University Medical Center, Leiden, the Netherlands. ${ }^{2}$ Department of Internal Medicine, Medical Center Haaglanden, the Hague, the Netherlands. ${ }^{3}$ Department of Nephrology, Erasmus University Medical Center, Rotterdam, the Netherlands.}

\section{Authors' contributions}

M.S. researched data and wrote manuscript, P.C.S researched data, M.D. reviewed manuscript, A.R.reviewed manuscript, S.B. contributed to discussion, reviewed manuscript. All authors read and approved the final manuscript.

\section{Competing interests}

The authors declare that they have no competing interests.

Received: 5 April 2011 Accepted: 5 July 2011 Published: 5 July 2011

\section{References}

1. Anand SS, Yusuf S: Risk factors for cardiovascular disease in Canadians of South Asian and European origin: a pilot study of the Study of Heart
Assessment and Risk in Ethnic Groups (SHARE). Clin Invest Med 1997, 20:204-210.

2. Forouhi NG, Sattar N, Tillin T, McKeigue PM, Chaturvedi N: Do known risk factors explain the higher coronary heart disease mortality in South Asians compared with European men? Prospective follow-up of the Southall and Brent studies, UK. Diabetologia 2006, 49:2580-2588.

3. Ross R: Atherosclerosis-an inflammatory disease. N Engl J Med 1999, , 340: 115-126.

4. Ostergaard J, Hansen TK, Thiel S, Flyvbjerg A: Complement activation and diabetic vascular complications. Clin Chim Acta 2005, 361:10-19.

5. Rus HG, Niculescu F, Vlaicu R: Co-localization of terminal C5b-9 complement complexes and macrophages in human atherosclerotic arterial walls. Immunol Lett 1988, 19:27-32.

6. Takahashi K, Ip WE, Michelow IC, Ezekowitz RA: The mannose-binding lectin: a prototypic pattern recognition molecule. Curr Opin Immunol 2006, 18:16-23.

7. Garred P, Larsen F, Seyfarth J, Fujita R, Madsen HO: Mannose-binding lectin and its genetic variants. Genes Immun 2006, 7:85-94

8. Saevarsdottir S, Oskarsson $\mathrm{OO}$, Aspelund T, Eiriksdottir G, Vikingsdottir T, Gudnason V, Valdimarsson $\mathrm{H}$ : Mannan binding lectin as an adjunct to risk assessment for myocardial infarction in individuals with enhanced risk. J Exp Med 2005, 201:117-125.

9. Thiel S, Holmskov U, Hviid L, Laursen SB, Jensenius JC: The Concentration of the C-Type Lectin, Mannan-Binding Protein, in Human Plasma Increases During An Acute Phase Response. Clin Exp Immunol 1992, 90:31-35.

10. Hansen TK, Tarnow L, Thiel S, Steffensen R, Stehouwer CD, Schalkwijk CG, Parving $\mathrm{HH}$, Flyvbjerg A: Association between mannose-binding lectin and vascular complications in type 1 diabetes. Diabetes 2004, 53:1570-1576.

11. Hansen TK, Gall MA, Tarnow L, Thiel S, Stehouwer CD, Schalkwijk CG, Parving HH, Flyvbjerg A: Mannose-binding lectin and mortality in type 2 diabetes. Arch Intern Med 2006, 166:2007-2013.

12. Best LG, Davidson M, North KE, MacCluer JW, Zhang Y, Lee ET, Howard BV DeCroo S, Ferrell RE: Prospective analysis of mannose-binding lectin genotypes and coronary artery disease in American Indians: the Strong Heart Study. Circulation 2004, 109:471-475.

13. Chandie Shaw PK, van Es LA, Paul LC, Rosendaal FR, Souverijn JH, Vandenbroucke JP: Renal disease in relatives of Indo-Asian Type 2 diabetic patients with end-stage diabetic nephropathy. Diabetologia 2003, 46:618-624.

14. Siezenga MA, Chandie Shaw PK, van der Geest RN, Mollness TE, Daha MR, Rabelink TJ, Berger SP: Enhanced complement activation is part of the unfavourable cardiovascular risk profile in South Asians. Clin Exp Immunol 2009, 157:98-103.

15. Roos A, Dieltjes P, Vossen RH, Daha MR, de Knijff P: Detection of three single nucleotide polymorphisms in the gene encoding mannosebinding lectin in a single pyrosequencing reaction. I Immunol Methods 2006, 309:108-114

16. Berger SP, Roos A, Mallat MJ, Fujita T, de Fijter JW, Daha MR: Association between mannose-binding lectin levels and graft survival in kidney transplantation. Am J Transplant 2005, 5:1361-1366.

17. Roos A, Garred P, Wildenberg ME, Lynch NJ, Munoz JR, Zuiverloon TC, Bouwman LH, Schlagwein N, Fallaux van der Houten FC, Faber-Krol MC, Madsen HO, Schwaeble WJ, Matsushita M, Fujita T, Daha MR: Antibodymediated activation of the classical pathway of complement may compensate for mannose-binding lectin deficiency. Eur J Immunol 2004 34(9):2589-2598.

18. Prasad GV, Vangala SK, Silver SA, Wong SC, Huang M, Rapi L, Nash MM, Zaltzman JS: South Asian ethnicity as a risk factor for major adverse cardiovascular events after renal transplantation. Clin J Am Soc Nephrol 2011, 6(1):204-2011.

19. Fischbacher CM, Bhopal R, Povey C, Steiner M, Chalmers J, Mueller $G$, Jamieson J, Knowles D: Record linked retrospective cohort study of 4.6 million people exploring ethnic variations in disease: myocardial infarction in SOuth Asians. BMC Public Health 2007, 7:142.

20. Nijjar AP, Wang H, Dasgupta K, Rabi DM, Quan H, Khan NA: Outcomes in a diabetic population of South Asians and whites following hospitalization for acute myocardial infarction: a retrospective cohort study. Cardiovasc Diabetol 2010, 22(9):4-11 
21. Madsen HO, Videm V, Svejgaard A, Svennevig JL, Garred P: Association of mannose-binding-lectin deficiency with severe atherosclerosis. Lancet 1998, 352:959-960

22. Ohlenschlaeger T, Garred P, Madsen HO, Jacobsen S: Mannose-bindinglectin variant alleles and the risk of arterial thrombosis in systemic lupus erythematosus. N Engl J Med 2004, 351(5):260-267.

23. Keller TT, van Leuven SI, Meuwese MC, Wareham NJ, Luben R, Stroes ES, Hack E, Levi M, Khaw KT, Boekholdt SM: Serum levels of mannose-binding lectin and the risk of future coronary artery disease in apparently healthy men and women. Arterioscler Thromb Vasc Biol 2006, 26:2345-2350.

24. Best LG, Ferrell RE, DeCroo S, North KE, MacCluer JW, Zhang Y, Lee ET, Howard BV, Umans J, Palmieri V, Garred P: Genetic and other factors determining mannose-binding lectin levels in American Indians: the Strong Heart Study. BMC Med Genet 2009, 10(5).

25. Tertov W, Sobenin IA, Tonevitsky AG, Orekhov AN, Smirnov VN: Isolation of atherogenic modified (desialylated) low density lipoprotein from blood of atherosclerotic patients: separation from native lipoprotein by affinity chromatography. Biochem Biophys Res Commun 1990, 167:1122-1127.

26. Alipour A, van Oostrom AJHHM, van Wijk JPH, Verseyden C, PLokker HWM, Jukema JW, Rabelink AJ, Castro Cabezas M: Mannose binding lectin deficiency and triglyceride-rich lipoprotein metabolism in normolipidemic subjects. Atherosclerosis 2009, 206:444-450.

27. Rugonfalvi-Kiss S, Endrész V, Madsen HO, Burian K, Duba J, Prohaszka Z, Karadi I, Romics L, Gönczöl E, Füst G, Garred P: Association of Chlamydia pneumonia with coronary artery disease and its progression is dependent on the modifying effect of mannose-binding lectin. Circulation 2002, 106:1071-1076.

28. Walsh MC, Bourcier T, Takahashi K, Shi L, Busche MN, Rother RP, Solomon SC, Ezekowitz AB, Stahl GL: Mannose-binding lectin is a regulator of inflammation that accompanies myocardial ischemia and reperfusion injury. I Immunol 2005, 175:541-546.

29. Collard CD, Montalto MC, Reenstra WR, Buras JA, Stahl GL: Endothelial oxidative stress activates the lectin complement pathway: role of cytokeratin 1. Am J Pathol 2001, 159:1045-1054.

30. Matthijsen RA, de Winther MPJ, Kuipers D, van der Made I, Weber C, Herias V, Gijbels MJJ, Buurman WA: Macrophage-specific expression of Mannose-binding lectin controls atherosclerosis in low-density lipoprotein receptor-deficient mice. Circulation 2009, 119:2188-2195.

31. Garred P, Flemming Larsen, Madsen $\mathrm{HO}$, Koch C: Mannose-binding lectin deficiency-revisited. Mol Immunol 2003, 40:73-84.

doi:10.1186/1475-2840-10-60

Cite this article as: Siezenga et al.: Low Mannose-Binding Lectin (MBL) genotype is associated with future cardiovascular events in type 2 diabetic South Asians. A prospective cohort study. Cardiovascular Diabetology 2011 10:60.

\section{Submit your next manuscript to BioMed Central and take full advantage of:}

- Convenient online submission

- Thorough peer review

- No space constraints or color figure charges

- Immediate publication on acceptance

- Inclusion in PubMed, CAS, Scopus and Google Scholar

- Research which is freely available for redistribution

Submit your manuscript at www.biomedcentral.com/submit 